\title{
Saúde mental e trabalho: um levantamento da literatura nacional nas bases de dados em Psicologia da Biblioteca Virtual de Saúde (BVS)
}

\section{Mental health and work: a survey of Brazilian literature in Biblioteca Virtual da Saúde (BVS) databases}

\author{
Lucia Kaori Masumoto $^{1}$; Carla Júlia Segre Faiman²
}

\begin{abstract}
Masumoto LK; Faiman CJS. Saúde mental e trabalho: um levantamento da literatura nacional nas bases de dados em Psicologia da Biblioteca Virtual de Saúde (BVS). Saúde, Ética \& Justiça. 2014;19(1);1-11.

RESUMO: Este trabalho é uma revisão da literatura nacional a respeito da relação entre saúde mental e trabalho. Foram buscados artigos referentes a este tema, publicados nas bases de dados reunidas na Biblioteca Virtual da Saúde (BVS) Index Psi, PePSIC e PSICODOC, no período entre 2008 e 2012. Para tanto, foram utilizados os descritores "saúde mental" e "trabalho", que foram buscados na BVS. Foram selecionados 33 artigos, distribuídos da seguinte forma nas bases de dados: 12 artigos no Index Psi, 8 no PePSIC e 13 na PSICODOC. Os dados das publicações foram organizados de acordo com os temas mais frequentes, que seriam: O papel da Psicologia e dos saberes correlacionados dentro do campo da Saúde Mental Relacionada ao Trabalho; Organização do trabalho; Formas de enfrentamento do sofrimento; Fatores de risco e de proteção; O sofrimento e o adoecimento. Da análise dos textos pode-se destacar que, no que se refere ao papel da Psicologia como ferramenta de intervenção, parece haver uma divisão entre as atuações de psicólogos clínicos e de psicólogos organizacionais, faltando uma integração entre as diferentes abordagens. Quanto a fatores que contribuem para o sofrimento/adoecimento relacionado ao trabalho, verifica-se que aspectos da organização do trabalho, falta de reconhecimento, cobrança de metas, formas de gestão ou postos de trabalho que resultem em isolamento do trabalhador podem ter efeitos nocivos para os trabalhadores.
\end{abstract}

\footnotetext{
1. Programa de Aprimoramento Profissional do Hospital das Clínicas da Faculdade de Medicina da Universidade de São Paulo "Saúde e Trabalho". Psicóloga do Instituto de Medicina Social e de Criminologia de São Paulo - IMESC. E-mail: lucia. masumoto@gmail.com

2. Departamento de Medicina Legal, Ética Médica e Medicina Social e do Trabalho da Faculdade de Medicina da Universidade de São Paulo. E-mail: cfaiman@uol.com.br
} 


\section{Introdução}

A relação entre saúde mental e trabalho é complexa, de forma que é difícil estabelecer, em cada caso, até que ponto o trabalho contribui com o sofrimento psíquico do trabalhador. O trabalho tende a ocupar uma dimensão central na vida de um sujeito, contudo, há outros aspectos, como família ou doença, que podem contribuir para o sofrimento mental e estes fatores interagem entre si, numa dinâmica que varia de acordo com cada indivíduo e a sua história de vida, sendo que cada um irá atribuir um significado pessoal à dimensão e à importância do trabalho.

De acordo com Seligmann-Silva ${ }^{1}$, o trabalho, dependendo da situação, pode tanto favorecer a saúde mental quanto pode levar o trabalhador, ou o seu coletivo, a distúrbios psicossociais, com o aparecimento de doenças psicossomáticas ou psiquiátricas. No entanto, realizar essa associação não é tão simples, como apontam Glina, Rocha, Batista e Mendonça ${ }^{2}$, que indicam a existência de dificuldades em reconhecer distúrbios psíquicos relacionados ao trabalho durante avaliações clínicas, dada a diversidade dos modos de adoecer e das manifestações do sofrimento e a complexidade da questão.

Um aspecto importante do trabalho é que, por muito tempo, desde a antiguidade, os trabalhadores que pensavam e planejavam as tarefas eram os mesmo que as executavam. No entanto, com o taylorismo e o fordismo, o trabalho foi fragmentado: a tarefa de pensar na melhor forma de se executar o trabalho foi separada da atividade de executá-lo ${ }^{1}$. Isso acarretou sérios prejuízos para a identidade do trabalhador, pois, conforme observa Braverman $^{3}$, o que para a gerência significa maior eficiência e lucratividade, para o trabalhador repercute numa alienação progressiva em relação aos processos de trabalho, de forma que este passou a ser desinteressante e estranho àqueles que o executam. Essa fragmentação oriunda da divisão do trabalho tem por finalidade tanto a intensificação do seu ritmo, como também um controle rigoroso sobre o desempenho de cada trabalhador ${ }^{1}$. Essa forma de se conceber a organização do trabalho, além de gerar impactos na identidade do trabalhador, pode gerar sérios prejuízos na saúde mental do indivíduo, pois, de acordo com Dejours ${ }^{4}$, com a fragmentação, as tarefas perdem seu sentido, prejudicando a qualidade do investimento emocional necessário para sua realização e o livre funcionamento do aparelho psíquico.

Desde então, as organizações de trabalho se diversificaram, surgindo novas demandas e dificuldades para os trabalhadores. $\mathrm{O}$ avanço tecnológico, além dos benefícios, traz constantes desafios e reformulações às atividades profissionais. Um novo vocabulário tem feito parte do cenário atual do trabalho, com termos como "flexibilização, comprometimento, empreendedorismo, empowerment, requalificação, qualidade total, jornada flexível, empregabilidade, desemprego estrutural, globalização, dentre outras" ${ }^{5}$ (p.31). Apesar deste novo cenário, ainda persistem antigas formas de trabalho convivendo na atualidade, conforme exemplifica Ianni (citado por $\mathrm{Sato}^{5}$ ), ao citar o trabalho escravo que faz parte da teia produtiva de grandes empresas ainda hoje no Brasil, ou a convivência, nas fábricas de linhas de montagem fordistas, com máquinas de tecnologia de última geração. Isso indica que as alterações decorrentes da implantação de novas tecnologias não resolveram antigos problemas relacionados à organização do trabalho. Em vez disso, novas questões e dificuldades têm se colocado.

Dentro deste panorama, Seligmann-Silva ${ }^{1}$ apontou que existem várias disciplinas que têm sistematizado os estudos sobre a interação entre os processos de saúde e doença relacionados ao trabalho, especialmente em relação aos fenômenos mentais, sendo que nesses estudos são buscados todos os aspectos que podem levar ao adoecimento relacionado ao trabalho. Tais disciplinas podem ser divididas em dois tipos, segundo a autora: aquelas que focam a questão da saúde humana em seus inúmeros aspectos e aquelas que lidam, de forma direta ou indireta, com o trabalho humano, sem que a saúde seja um foco formal de estudo. As disciplinas que merecem destaque no primeiro grupo são: psicodinâmica do trabalho, ergonomia, psicanálise, medicina do trabalho, psicologia do trabalho, medicina psicossomática, toxicologia, psicofisiologia, neurofisiologia e a psiquiatria. Já no segundo grupo se encontram as seguintes disciplinas: economia política, organização do trabalho, filosofia e sociologia. Cada um desses elementos enriquece o campo de estudos das relações entre saúde mental e trabalho através de suas peculiaridades nas formas de pensar, ao mesmo tempo em que realizar uma integração entre as diferentes áreas pode ser uma tarefa árdua.

Dessa diversidade de disciplinas que estudam a relação entre saúde/doença e trabalho, podemos depreender que tal campo é complexo, de forma que são vários os aspectos que devem ser levados em consideração, e também em sua dinâmica, para se ter uma mínima compreensão sobre o sofrimento mental pelo qual passa o trabalhador adoecido por questão do trabalho.

É dentro deste vasto campo que se propõe um levantamento das publicações acerca da relação entre saúde mental e trabalho, com o objetivo de verificar o que se tem estudado a respeito desse tema no Brasil. Interessa, portanto, apresentar e discutir as questões que têm recebido a atenção dos pesquisadores no campo da Saúde mental relacionada ao trabalho. 


\section{Método}

Foi realizado um levantamento da literatura nacional em 23 de outubro de 2012, sobre o tema proposto, especificamente em bases de dados que indexam periódicos científicos em psicologia e áreas afins. Para tanto, foram utilizados os descritores "saúde mental" e "trabalho", que foram buscados na BVS (Biblioteca Virtual de Saúde).

Foram utilizadas as seguintes bases de dados eletrônicas: Index Psi Periódicos Técnico - Científicos (Index Psi), o portal de Periódicos Eletrônicos de Psicologia (PePSIC) e a Base de dados bibliográfica de Psicologia (PSICODOC). Através dessas bases de dados foi feita pesquisa eletrônica com os descritores "saúde mental" e "trabalho", que foram buscados na BVS (Biblioteca Virtual de Saúde), utilizando-se o operador booleano "AND" entre os dois descritores, para que os resultados da pesquisa contemplassem principalmente artigos que contivessem esses dois termos.

Como critérios de inclusão foram considerados artigos com textos completos e disponíveis online, que tivessem relação direta com o tema proposto, compreendidos no período entre 2008 e 2012. Foram excluídos os artigos que tinham o tema da saúde mental relacionada ao trabalho como secundário aos seus temas principais.

Após o levantamento de artigos, estes foram lidos na íntegra e foram organizados de acordo com os temas mais frequentes.

\section{Resultados e discussão}

De acordo com os critérios de inclusão e exclusão supracitados, foram selecionados 33 artigos, distribuídos da seguinte forma nas bases de dados: 12 artigos no Index Psi, 8 no PePSIC e 13 na PSICODOC. Para a análise, os artigos foram divididos em cinco grupos de acordo os temas tratados, a saber: $O$ papel da psicologia e dos saberes correlacionados dentro do campo da Saúde Mental Relacionada ao Trabalho, com 9 artigos; Organização do trabalho, com 13 artigos; Formas de enfrentamento do sofrimento, com 12 artigos; Fatores de risco e de proteção, com 11 artigos; $O$ sofrimento e o adoecimento, com 21 artigos. Vários artigos se encaixaram em mais de um grupo pela abrangência de sua abordagem, o que explica que a soma de textos dos grupos seja maior do que o total de artigos. Pela proposta do presente estudo, não será possível tratar de cada um dos artigos separadamente. Optamos, então, por apresentar as ideias mais representativas de cada tema.

Tema 1 - O papel da psicologia e dos saberes correlacionados dentro do campo da Saúde Mental Relacionada ao Trabalho

Dentro desse tema serão discutidas as publicações que tiveram como um de seus objetivos de pesquisa entender como a psicologia pode intervir dentro do campo da Saúde Mental Relacionada ao Trabalho, como também como a psicologia tem lidado com essa temática. Foi possível relacionar 9 artigos com este tema.

Nos resultados encontrados por Abs e Monteiro ${ }^{6}$ existem dois tipos de intervenções praticadas pelos psicólogos em seus consultórios particulares em relação às queixas de seus pacientes sobre o trabalho: aquelas que excluem a questão do trabalho, e aquelas que contemplam o fator "trabalho". No primeiro tipo, são buscados outros elementos para o sofrimento psíquico que estejam fora da questão do trabalho, apesar de a queixa do paciente relacionar diretamente o seu sofrimento com o trabalho. Já nas intervenções que levam em consideração o trabalho, este é pensado como algo singular e particular para cada indivíduo, assim, os psicólogos atuam de forma a acolher o sofrimento e auxiliar na reinserção do indivíduo ao mercado de trabalho. Também são indicadas outras atividades para o alívio do sofrimento, tais como busca de um psiquiatra, ioga e ginástica.

Em outro estudo, Gibert e Cury $^{7}$ investigaram, através de uma pesquisa qualitativa, como os psicólogos organizacionais vêm promovendo a saúde mental dos trabalhadores. Foi possível apreender nas falas dos psicólogos organizacionais que existe uma dicotomia nas práticas psicológicas: há aqueles que realizam a chamada psicologia aplicada, e que se inserem somente em tarefas como recrutamento, treinamento e seleção; e existem os psicólogos que realizam a escuta, o acolhimento e a orientação dos trabalhadores, configurando, desta forma, uma prática clínica. Essa dicotomia gerou nos pesquisados psicólogos organizacionais desconforto em relação à sua própria prática, pois nas organizações não tem havido espaço para o atendimento clínico, como alguns dos pesquisados gostariam que houvesse. Em vez de se abrir espaço para uma integração entre as duas práticas, elas são fragmentadas, cabendo ao psicólogo que atua no ambulatório este segundo papel, o que lida diretamente com a saúde mental dos trabalhadores.

Para Bendassolli ${ }^{8}$ a psicologia se apropriou da questão do trabalho através de "três psicologias do trabalho, a saber: a industrial, organizacional e do trabalho" (p. 77), sendo que a primeira se inseriu no mundo do trabalho principalmente através das tarefas de seleção e recrutamento de trabalhadores, e pensa o trabalho como emprego, ou seja, atividade destinada à produção de valor econômico, assim o foco de intervenção desta psicologia é na eficácia e eficiência do trabalhador. A segunda surge quando a "empresa" passa a ser vista como uma "organização", e assim o seu principal tema é a relação entre o indivíduo e a sua organização, sendo que aqui o trabalho também é visto como emprego, no entanto, o indivíduo é visto como ser social, como também como sujeito cognitivo, e o foco 
de ação da psicologia organizacional é no desempenho eficaz. Já a terceira é uma abordagem mais recente, e que pensa a relação entre o indivíduo e o trabalho, sendo que o trabalho não se reduz ao emprego. O trabalho é pensado como central na estruturação psíquica do indivíduo, de forma que a intervenção neste caso não se dá somente em torno da eficiência, como também leva em consideração o significado particular que cada indivíduo tem do seu trabalho.

As publicações relacionadas à inserção do psicólogo no mundo do trabalho demonstram que os saberes se encontram fragmentados, nos quais psicólogos organizacionais têm funções diferentes dos psicólogos clínicos do trabalho. Em muitos casos, além dessa fragmentação, não existe a comunicação entre os saberes de forma que a compreensão sobre o processo de trabalho encontra-se incompleta. Em alguns casos, o saber psicológico esteve atento apenas às questões intrapsíquicas, ignorando o contexto maior no qual estão inseridos os trabalhadores.

Pode-se perceber também que o conhecimento que o campo da psicologia produz pode auxiliar no entendimento da relação entre o homem e o trabalho, e, assim, como esta relação se modifica ao longo do tempo, a psicologia também acaba por modificar o seu olhar sobre ela. De forma geral, pode-se observar que os conceitos de algumas vertentes da psicologia auxiliam na hora de se avaliar uma situação de trabalho, o que pode trazer esclarecimento, especialmente em situações de conflito.

\section{Tema 2 - Organização do trabalho}

Neste tema serão tratadas as publicações que relatam, tanto as consequências que a organização do trabalho tem sobre a saúde mental dos trabalhadores, como também alguns aspectos que, à primeira vista, não parecem estar relacionados à organização do trabalho, mas que também são fundamentais na compreensão do sofrimento que pode ser gerado por aspectos da atividade profissional. Dentro deste tema foi possível classificar 13 artigos. A Divisão sexual do trabalho e o Trabalho imaterial são aqui tratados como subtemas, tendo aparecido, respectivamente, em 2 e em 4 artigos dentre os 13 selecionados.

A organização do trabalho pode ser caracterizada a partir dos seguintes fatores: a divisão hierárquica entre os homens, o conteúdo das tarefas, a divisão do trabalho, as relações de poder, as responsabilidades, entre outros ${ }^{4}$.

Em pesquisa realizada sobre a sobrecarga de trabalho e a sua contribuição para o adoecimento de trabalhadores de um polo industrial, Carvalho e Moraes ${ }^{9}$ através de entrevista individual semi-estruturada, tiveram como resultado o fato de que a sobrecarga de trabalho e a pressão por metas de qualidade e produtividade, decorrentes da organização do trabalho, tem um forte caráter patogênico. Tal organização do trabalho, favorecida pelo tipo de gestão da qualidade total, tornou o trabalho real cada vez mais distante do trabalho prescrito, e o controle sobre os trabalhadores se tornou mais rígido. Como resultados de pesquisa sobre a relação entre saúde física e mental de docentes de cursos de pósgraduação stricto-sensu cujo conceito CAPES é recebido pelo esforço de produção, Cassandre ${ }^{10}$ se deparou com o fato de que, quanto maior o conceito do curso, mais seguro é o docente em relação às condições materiais e mais ele está satisfeito com as suas relações interpessoais, sendo que o inverso também é verdadeiro. Como hipótese, o autor teorizou que possivelmente os docentes com menor conceito CAPES fiquem mais isolados, de forma que até o seu tempo de descanso seja utilizado em prol das pesquisas, por existir a preocupação de elevar o conceito CAPES, o que acaba por acarretar todos esses prejuízos em suas vidas. Já os docentes com os conceitos mais altos, provavelmente já não se preocupam tanto em mudar o quadro do seu programa de pós-graduação, no entanto, eles ainda devem ser pressionados no sentido de manter a qualidade de seus cursos.

Como discussão, Cassandre ${ }^{10}$ coloca que a pósgraduação brasileira está formatada nos mesmos moldes das organizações capitalistas, e que dela é exigida alta produção somente, sem que seja considerada uma produção genuína do conhecimento da produção docente. Além disso, tem-se diminuído o tempo de formação dos pós-graduandos, o que afeta diretamente a qualidade de produção destes. Em conclusão, o autor aponta que a saúde física e mental dos docentes está diretamente ligada a essa forma de produção semelhante às de organizações capitalistas e ressalta a importância de os gestores desses programas pensarem em novas formas de se manter a produtividade, mas que, ao mesmo tempo, permitam o pensamento acadêmico livre, de forma que seja respeitado o tempo de uma pesquisa de qualidade, e, consequentemente, que os sujeitos sejam respeitados em sua saúde.

Assim, foi possível observar que o tipo de organização que utiliza uma gestão na qual se valoriza principalmente a produção, em detrimento da saúde dos trabalhadores, tem gerado grande insatisfação entre aqueles que se encontram «amarrados» a essa organização.

\section{Divisão sexual do trabalho}

Em algumas publicações foi abordada a questão dos gêneros dentro do contexto de trabalho, apesar de esse tema ter sido pouco relatado em termos de número de publicações.

Cunha e Vieira ${ }^{11}$, ao pesquisarem o trabalho das labirinteiras*, verificaram que o trabalho é realizado em ambiente doméstico, de forma que a realização de tarefas 
domésticas e o cuidado com as crianças cabem somente às mulheres, mesmo que os homens (marido e filhos) estejam ociosos. E isso ocorre através de um processo de naturalização destas tarefas como atribuição às mulheres, pelo aparente fato de serem naturalmente melhores nisso do que os homens, não se vendo este fato como uma construção social. Nesse sentido, as labirinteiras acabam por escolher o labirinto como trabalho por ser possível a conciliação entre este e a vida familiar. O labirinto é uma atividade visivelmente considerada feminina, a ponto de os homens que exercem tal atividade o fazerem de forma escondida para evitar questionamento a respeito de sua masculinidade ${ }^{11}$.

Em pesquisa realizada com bombeiros, estes defendem que na corporação existe a igualdade de gêneros, e a única diferença apontada, tanto pelos homens como pelas mulheres, é sobre a questão da força física. Para a maioria destes profissionais não há sentido em separar as atividades masculinas das femininas, ou até mesmo dizer que um é melhor que o outro. No entanto, para alguns, as mulheres deveriam ser restritas a determinadas atividades, com uma formação diferenciada, visto que, por terem mais força, os homens têm que compensar o trabalho feminino, especialmente nas atividades operacionais, comprometendo a produtividade. Outros apontam que as mulheres têm capacidades específicas para o trabalho, como no trato em ocorrências com mulheres e famílias, pois para eles as mulheres têm uma abordagem específica que ajuda no estabelecimento do diálogo e conforto às vítimas. As mulheres reconhecem que podem ser tão boas ou melhores na realização de algumas atividades prescritas, mas elas sentem que têm que provar o tempo todo que são boas profissionais, mesmo em tarefas que não envolvam força física. Elas sentem que alguns homens se consideram superiores, e que às vezes não admitem que elas trabalhem na mesma equipe, e se incomodam quando as mulheres se mostram mais habilidosas do que eles. Além dessa desvalorização do trabalho feminino, às vezes elas se sentem superprotegidas pelos homens e também acham que os homens não confiam no trabalho delas ${ }^{12}$.

Através dessas publicações foi possível verificar que existe uma naturalização do que seria um trabalho feminino e do que seria o trabalho masculino, de forma que, na pesquisa realizada entre os bombeiros $^{12}$, que poderia ser classificado como um "trabalho masculino", de acordo com essa naturalização, as mulheres se sentem desvalorizadas, a ponto de sentirem que têm de provar que são boas profissionais, o que pode gerar sobrecarga. A sobrecarga também pode ocorrer quando há dupla jornada de trabalho, ou seja, além do trabalho remunerado, algumas mulheres se vêem obrigadas a cumprir as tarefas domésticas e a cuidar dos filhos ${ }^{13}, 14$, sendo que muitas vezes as mulheres acabam escolhendo o seu trabalho de acordo com essas "obrigações" que elas têm dentro de casa, como no caso da pesquisa com as labirinteiras ${ }^{11}$.

\section{Trabalho imaterial}

Grisci ${ }^{15}$ denomina como trabalho imaterial "o conjunto de atividades corporais, intelectuais, criativas, afetivas e comunicativas inerentes ao trabalhador, atualmente valorizadas e demandadas como condição indispensável à produção." (p. 5), e deste tipo de trabalho resultam não apenas produtos concretos, como também são produzidos afetos, tais como segurança, conforto e confiança, criando-se um novo tipo de relação entre produção e consumo.

O trabalho imaterial vem ganhando espaço na medida em que há um abandono crescente do modelo de produção fordista, que é acompanhado das novas formas de tecnologias da informação e comunicação e, como consequência, a instalação de modos sutis de controle. Tais características acabam por intensificar o tempo do trabalho, ao mesmo tempo em que se moldam as subjetividades, uma vez que o objetivo da organização do trabalho não é apenas a maximização da força física, mas é também a exploração máxima da criatividade dos trabalhadores nas suas tarefas ${ }^{15}$.

Merlo, Traesel e Baierle ${ }^{16}$ discutem a questão do trabalho imaterial através de pesquisas realizadas com duas categorias profissionais diferentes, enfermeiros e guardas municipais. No artigo citado conclui-se que tanto os enfermeiros como os guardas municipais, apesar de realizarem trabalhos bastante diferentes, sofrem com o fato de que os trabalhos que eles realizam não podem ser mensurados ou ser vistos em termos de concretude, pois o que eles produzem, respectivamente, são cuidado e segurança. No caso da enfermagem, é comum que esses trabalhadores não respeitem o limite do próprio corpo e acabem se sobrecarregando no trabalho, e isso é atribuído à internalização do controle e das exigências, situação que também pode ser observada nos resultados da pesquisa de Secco, Robazzi, Souza e Shimizu ${ }^{17}$. Já com os guardas municipais existe a sensação de que nada foi produzido, pois o que se pretende nesse trabalho é justamento evitar que algo aconteça, e não o acúmulo de produção. Tal sensação foi descrita no estudo realizado com guardas municipais $^{16,18,19}$, no qual relata-se que, como não há

\footnotetext{
* Labirinteiras são trabalhadoras que realizam um tipo de bordado bastante trabalhoso denominado labirinto, em que podem ser fabricadas tanto peças de decoração como de também vestuário.
} 
produção concreta no trabalho, os guardas sentem que não fizeram nada, o que gera muita frustração.

Agentes de segurança penitenciária acabam tendo as suas relações familiares e sociais invadidas pelas dinâmicas institucionais, com comportamentos compulsivos antes de iniciar o sono, como a verificação de trancas das portas e janelas e a averiguação das condições de segurança de suas casas. A internalização dos valores e regras da população carcerária também pode ser vista na utilização da linguagem destes profissionais mesmo fora do ambiente de trabalho ${ }^{20}$.

A dimensão do trabalho imaterial foi pouco abordada nas publicações, mas ela se mostra como algo extremamente relevante, pois é algo que tem acometido várias categorias de trabalho, principalmente aquelas nas quais não se tem uma produção concreta, o que pode gerar a sensação de que nada foi feito, especialmente nas situações em que não houve resolução de um problema determinado. Apesar dos efeitos do trabalho imaterial terem maior evidência nestes tipos de trabalho, pode-se pensar que este é um aspecto que vem dominando todos os tipos de trabalho, pois os problemas que não foram resolvidos no expediente de trabalho podem ficar retidos na mente do trabalhador, de forma que, na verdade, ele esteja trabalhando vinte e quatro horas por dia. O controle não é mais externo, como era no modelo fordista, ele passou a ser internalizado pelos próprios trabalhadores, $\mathrm{o}$ que acaba favorecendo a sobrecarga de trabalho.

Outro aspecto importante a ser discutido é a contaminação da vida social pelo trabalho, pois, em muitos trabalhos, especialmente naqueles que envolvem grande risco, os trabalhadores acabam tendo que desenvolver formas de enfrentamento para lidar com essas situações, o que acaba por moldar a sua percepção sobre o mundo, e, consequentemente, a sua forma de lidar com este.

\section{Tema 3 - Formas de enfrentamento do sofrimento}

Aqui serão listados os tipos de enfrentamento encontrados nas publicações, sendo que elas variam de acordo com a categoria profissional, ou mesmo de pessoa para pessoa, quando não há uma coesão grupal definida. Com este tema foi possível relacionar 12 artigos.

Uma das estratégias mais utilizadas pelos trabalhadores para o enfrentamento do sofrimento e da doença é a própria negação destes para que seja possível dar continuidade ao trabalho, como pode ser observado nas publicações de Carvalho e Moraes ${ }^{9}$, Baierle e Merlo $^{18}$ e Merlo et al. ${ }^{16}$. Em pesquisa de Carvalho e Moraes $^{9}$ também aparece como estratégia defensiva a autoaceleração do ritmo de trabalho, na tentativa não só de negar o sofrimento, mas, também, como forma de obter o reconhecimento no ambiente de trabalho.

Outra forma de enfrentamento utilizada por guardas municipais, em estudo realizado por Baierle e $\mathrm{Merlo}^{18}$, é o alcoolismo e a drogadição. Apesar de serem problemas de saúde, nesta pesquisa eles acabam por se configurar como estratégias de enfrentamento, pois eles surgem principalmente nos postos de atendimento fixo, ou seja, nos lugares nos quais esses trabalhadores se encontram sós. Desse modo, o alcoolismo e a drogadição acabam por se tornar as principais formas de entorpecimento contra uma realidade ansiogênica, pois, nos seus postos de trabalho, não é possível realizar trocas entre colegas, situação que também é configurada como outra forma de enfrentamento nessa mesma pesquisa, que só é possível ocorrer em outros postos de trabalho, nos quais existe a cooperação entre os trabalhadores. Em alguns resultados de pesquisas, tem-se sugerido a criação de espaços para a discussão, de forma a se constituir um espaço terapêutico para que os trabalhadores possam falar das suas vivências de prazer e sofrimento, das suas dificuldades, trocar experiências e saberes, como também para a discussão de algumas situações que ocorrem no trabalho ${ }^{16,18,21,22,23}$.

Os cursos de capacitação e atualização também foram referidos como importantes ferramentas contra a insegurança e a falta de prescrição sobre o que deve ser feito no trabalho, situações que geram muita angústia nos trabalhadores que muitas vezes não sabem o que fazer quando se deparam com situações difíceis ${ }^{21,22,23,24}$.

Bottega e Merlo ${ }^{23}$, ao realizarem uma pesquisa com educadores sociais de adolescentes em situação de rua, verificaram que estes profissionais usam tanto estratégias de enfretamento consideradas pelos autores como positivas como negativas. As primeiras, tais como "ambivalência", "estar sempre alerta" e "enfrentamento das situações" (p. 272), buscam transformar a situação geradora de sofrimento, pois visam uma mobilização coletiva, enquanto que o segundo tipo de enfrentamento não gera essa mobilização nos trabalhadores, pois são estratégias individuais, e podem ser exemplificadas nas seguintes condutas: "banalização", "amortecimento e anestesia do sofrimento", "silenciamento" e "racionalização" (p.272).

Através destes resultados foi possível identificar que muitas estratégias de enfrentamento são comuns, e algumas são particulares a cada categoria profissional, aquilo que Dejours ${ }^{4}$ identificou como ideologia defensiva, que age da seguinte maneira: ela oculta uma ansiedade comum ao grupo, e atua como mecanismo de defesa coletiva contra a percepção dos riscos reais do trabalho, e aquele trabalhador que não compartilha dessa ideologia, acaba sendo excluído desse grupo social. Assim, o trabalhador excluído acaba tendo que criar os seus próprios mecanismos de defesa. Tal situação também ocorre quando a organização do trabalho não permite que haja trocas entre os trabalhadores, sendo assim impossível criar uma ideologia defensiva de um grupo. 
Chama a atenção como foi referida em várias pesquisas a necessidade de cursos de capacitação, pois é natural que o profissional recém-inserido se sinta inseguro num novo trabalho, no entanto, essa insegurança não é acolhida, ela parece passar a ser entendida como uma falha da sua própria formação, ou talvez, uma falha de si mesmo enquanto profissional.

Um problema verificado nestes resultados é a questão de se recorrer a estratégias individuais de enfrentamento, o que faz pensar nas causas do fato de os trabalhadores não se unirem contra a fonte de sofrimento. O que não permite que isso ocorra? Como hipóteses, podese pensar que, da forma como o trabalho está organizado, o trabalhador acaba por compreender que o sofrimento decorre da sua falta de capacidade ou habilidade em lidar com essas situações difíceis. Pode também não haver um espaço, ou uma cultura organizacional que favoreça as trocas entre os trabalhadores, para que estes pudessem verificar que todos eles sofrem por conta do trabalho. Nesse sentido, a proposta de criação de grupos terapêuticos é interessante por propiciar esse momento de trocas e acolhimento e, assim, possibilitar que se discutam formas de transformar a realidade na qual se encontram.

Uma outra hipótese para este tipo de situação (que não aparece nos artigos pesquisados) é considerar que a cultura organizacional estimule a competição entre os funcionários, o que prejudica a qualidade da interação e a manifestação de dificuldades, trazendo importantes consequências para os trabalhadores

\section{Tema 4 - Fatores de risco e de proteção}

Neste tema serão apontados os fatores de risco e de proteção para o sofrimento e o adoecimento no ambiente de trabalho. 11 artigos puderam ser relacionados com este tema.

Em uma revisão de literatura sobre o estresse enfrentado pelos enfermeiros em Unidades de Terapia Intensiva (UTI) adulta, verificou-se que os principais fatores predisponentes de estresse são: a sobrecarga de trabalho, os conflitos de funções, a desvalorização sentida por eles e as condições de trabalho. No entanto, havia também outros fatores, como a baixa remuneração, dupla jornada, a insatisfação com o trabalho, falta de autonomia, relacionamentos interpessoais, ruído, acidentes biológicos e morte de pacientes, que também contribuem para o estresse nas UTIs ${ }^{25}$.

Em conclusão de uma revisão de literatura sobre transtornos mentais relacionados ao trabalho, foram identificados como fatores de risco para o desenvolvimento de transtornos mentais as seguintes características: condições de trabalho inadequadas, pouca valorização do trabalhador, pouca participação nas decisões do trabalho, demandas excessivas no trabalho, trabalho em turnos, remuneração baixa, invisibilidade do trabalho realizado, trabalho altamente complexo, ausência de lazer e condições de trabalho indesejáveis, com múltiplos riscos ocupacionais ${ }^{26}$.

Para Job (citado por Ribeiro ${ }^{27}$ ), os fatores de risco para o sofrimento e adoecimento, decorrentes do trabalho são: a pressão e a responsabilidade no trabalho, a falta de convivência com a família, a falta de apoio no ambiente de trabalho, pouca autonomia e liberdade para realizar as tarefas, medo do desemprego e assédio moral. Por outro lado, os fatores protetores são: a autonomia, o reconhecimento, a autoestima, o respeito, a participação dos amigos e da família e o apoio dos colegas e chefes de trabalho. Ribeiro, Pessalacia, Mattos, Aramaki e Postteli ${ }^{28}$ também apontaram em sua pesquisa fatores de risco para o desenvolvimento de sofrimento e adoecimento: o desconforto físico, longas jornadas de trabalho, pressão e excesso de responsabilidades, sendo que tais fatores estão relacionados a alterações de sono, como também com a ansiedade.

Pode-se verificar, nesses resultados, que os fatores de risco e de proteção são comuns em várias categorias profissionais, apesar das suas peculiaridades. Merece destaque a importância que tem o reconhecimento de que o trabalho foi bem feito, ou que é importante, como fator protetor, e que permite a realização pessoal. A baixa remuneração, queixa comum, pode ser percebida como falta de reconhecimento, ou seja, o trabalhador entende que o seu salário não corresponde a todo o esforço empreendido na realização das tarefas, portanto, todo o seu valor não é reconhecido pela chefia que determina o seu salário.

\section{Tema 5 - O sofrimento e o adoecimento}

Para Dejours 4 “o sofrimento começa quando a relação homem-organização do trabalho está bloqueada; quando o trabalhador usou o máximo de suas faculdades intelectuais, psicoafetivas, de aprendizagem e de adaptação" (p. 52), ou seja, quando o trabalhador percebe que não há margem de manobra possível para que ele mude as condições que o incomodam, que acompanha a certeza que a insatisfação dele em relação ao trabalho não irá diminuir. Além disso, para Dejours ${ }^{4}$, tanto maior será o sofrimento quanto maior é a rigidez da organização do trabalho, quanto menos relevante é o trabalho, quanto mais acentuada é a divisão do trabalho e quanto menor é a possibilidade de mudar algo no trabalho.

Aqui serão tratados os artigos que versam sobre o sofrimento e o adoecimento relacionado ao trabalho. Neste tema foi possível relacionar 21 artigos, sendo que 2 versaram especificamente sobre o estresse e burnout, e 3 pesquisaram a questão do desemprego. Estes dois assuntos serão tratados como subtemas. 
Diante das doenças relacionadas ao trabalho, Carvalho e Moraes ${ }^{9}$ averiguaram que as chefias e colegas de trabalho que não haviam adoecido manifestavam descaso, omissão e banalização da doença. Além desse desdém em relação aos adoecidos, o direito à readaptação profissional não foi respeitado pela empresa, de forma que os adoecidos acabavam retornando para os postos nos quais eles adoeceram, e mesmo aqueles que não voltavam ao seu posto de trabalho original, acabavam por ficar sem posto e relatavam ser monitorados o tempo todo, o que gerava um sentimento de perseguição, fora a sensação de estar atrapalhando o trabalho dos outros. Nos relatos obtidos, os autores ainda destacam que o sofrimento relacionado ao trabalho decorria da fragilização da cooperação, da negação do sofrimento relacionado ao trabalho, do abismo que existe entre trabalho prescrito e trabalho real e, por fim, da individualização. Estas últimas condições são consequências da forma pela qual o trabalho é gerido e organizado.

O sofrimento psíquico acaba acompanhando a doença física, pois existe a pressão para retornar ao trabalho, o sentimento de culpa por ter adoecido, a humilhação por não ter a sua doença reconhecida e o preconceito e, por fim, há o temor de se perder o emprego, e, consequentemente, parte de sua identidade ${ }^{9}$.

Como conclusão de sua pesquisa, Carvalho e Moraes $^{9}$ observaram que o processo de adoecimento é influenciado por uma cadeia complexa de elementos: a sobrecarga de trabalho; a autoaceleração, utilizada como estratégia defensiva; a normopatização (que pode ser entendida como uma deformação do que se considera normal) das condições de trabalho e que acaba comprometendo a percepção do trabalhador em relação ao seu limite e adoecimento; a patologia da servidão voluntária na qual há uma submissão às condições de trabalho que podem desencadear uma doença; a negação de que as condições e a organização do trabalho podem conduzir ao adoecimento; individualismo que leva à fragilização da cooperação; e, por fim, a violência psicológica sofrida pelos trabalhadores que desenvolveram doenças ocupacionais diante do desdém da empresa e dos seus colegas de trabalho, o que leva ao seu isolamento. Consideramos que as modernas ferramentas de avaliação individualizada de produtividade, utilizadas em modelos de gestão que estimulam a competitividade, desempenham um papel da maior importância neste quadro, contribuindo para a deterioração do relacionamento entre colegas e das condições de trabalho.

Numa revisão de literatura sobre transtornos mentais relacionados ao trabalho, Bárbaro et al. ${ }^{26}$ discutiram que o trabalho, ou a falta dele, pode gerar transtornos mentais ou alterações psicossomáticas nos indivíduos. Em alguns dos artigos levantados, a sobrecarga de trabalho, os sistemas de plantões e o rodízio de horários atuam como fontes de pressão para o exercício do trabalho. O prolongamento da jornada de trabalho pode ativar o desgaste físico e psicológico do trabalhador, o que pode levar ao desencadeamento de estresse e sofrimento psíquico. Também foi verificado que os jovens trabalhadores estão mais propensos a desenvolver um transtorno mental relacionado ao trabalho do que quem tem mais experiência. Os trabalhadores mais acometidos são: 1-) professores, que estão expostos a ambientes cheios de conflitos e de elevada carga de trabalho, e os riscos que estes profissionais vivenciam são menos visíveis do que de outras categorias profissionais, assim, a saúde mental está diretamente relacionado à natureza do trabalho realizado pelos professores; 2-) trabalhadores de saúde, tais como enfermeiros e médicos, que lidam cotidianamente com pessoas em sofrimento e situações de emergência, além disso, estes profissionais costumam ter extensas jornadas de trabalho e são altamente exigidos; 3)- adultos, mulheres e donas-decasa, pois o trabalho doméstico é tido como de pouco valor social e invisível, o que traz repercussões negativas para a saúde mental das donas-de-casa; foi visto em uma das pesquisas que a prevalência de transtornos mentais comuns é maior em donas-de-casa $(43,3 \%)$ do que em trabalhadoras $(36,8 \%)$ em Feira de Santana (BA); 4-) trabalhadores de siderurgia, que por conta do trabalho realizado, estão propensos a sofrer fadiga, pois estes trabalhadores sofrem uma ampla gama de exigências e não encontram recursos para lidar com elas.

No trabalho dos educadores sociais que lidam com adolescentes em situação de rua, as relações interpessoais, tanto dos profissionais com os seus colegas de trabalho, como daqueles com os adolescentes, configuram-se como fonte de sofrimento e de prazer. Nesta última relação citada, foi visto que os educadores têm sentimentos opostos em relação aos adolescentes, e em grande intensidade, o que gera mobilização por parte dos educadores, pois o que eles acabam vendo no dia-a-dia é o fato de estes adolescentes serem vítimas de grande injustiça e falta de direitos. Apesar disso, os trabalhadores acreditam que podem fazer a diferença na vida destes adolescentes. Com relação aos colegas de trabalho, a fonte de sofrimento é apontada como a falta de envolvimento destes com o trabalho, perceptível através de ausências e atrasos ${ }^{23}$.

\section{Estresse e Burnout}

Para o modelo teórico de Maslach, a síndrome de Burnout é caracterizada inicialmente pelo aparecimento da Exaustão emocional, seguida da Despersonalização (definida como uma espécie de distanciamento em que as atividades e os relacionamentos parecem "impessoais", sem engajamento afetivo), e por fim, da diminuição do sentimento de Realização Pessoal no trabalho Santos et 
al. ${ }^{25}$. Assim, as autoras avaliaram, através do instrumento MBI (Maslach Burnout Invetory), a síndrome de Burnout nos profissionais que atendem vítimas de violência, e, como resultado, foi verificado que a dimensão da Exaustão Emocional aumenta na mesma proporção em que se eleva a insatisfação no trabalho, junto da percepção de que o trabalho atua como fonte de estresse que prejudica a saúde. Quanto à Despersonalização, esta diminui na medida em que se aumenta o tempo de experiência, e aumenta na mesma proporção em que se percebe que o trabalho vem trazendo prejuízos à saúde emocional. A dimensão da Realização Pessoal está mais preservada naqueles que trabalham na instituição em tempo integral, e uma explicação para isso é a possibilidade que estes profissionais têm de poder acompanhar melhor os frutos de seu trabalho.

Dados obtidos em pesquisa de Santos e Cardoso ${ }^{22}$ apontam que um número considerável de profissionais de saúde mental estudados apresentou manifestação de estresse. Como hipótese, foi pensado que essa manifestação de estresse está relacionada ao tipo de trabalho, no qual os profissionais lidam com situações que podem levar à vulnerabilidade emocional, pelo contato constante com pessoas em sofrimento. Com relação ao burnout, verificou-se que os profissionais apresentaram alto índice de esgotamento emocional e despersonalização, no entanto, também mostraram alta realização pessoal. A esta última constatação, foi pensado que provavelmente estes profissionais, por mais que tenham que enfrentar condições adversas, estão neste trabalho por escolha própria, o que traz satisfação.

O desgaste parece ser constante em trabalhos que envolvem o contato direto com pessoas, como na área da saúde. Ribeiro e Martins ${ }^{27}$ apontam em sua pesquisa como o desgaste está presente no cotidiano dos trabalhadores de Unidade de Saúde da Família (USF), seja através do aumento do número de consultas eventuais (aquelas que não são agendadas), ou pela realização de grupos que costumam ter uma boa resolubilidade, o que gera prazer, no entanto, tal atividade gera intenso desgaste, pois a ocorrência desta não tem resultados rápidos, e às vezes inclui um manejo difícil. O desgaste também provém do sentimento de impotência, comum em situações como a não aderência do usuário ao tratamento, e também a falta de rede de apoio para os encaminhamentos dos usuários. Os sinais de sofrimento apresentados foram "desânimo, angústia, conflito na equipe, queixa de falta de rede de apoio, acúmulo de atividades, atribuição dos problemas do usuário a si mesmo, desvalorização profissional, sobrecarga de trabalho e impotência ante a dificuldade de dar conta da demanda" (p. 248).

\section{Desemprego}

Barros e Oliveira ${ }^{29}$ realizaram uma pesquisa com o intuito de compreender a relação entre o desemprego e a saúde mental do trabalhador desempregado e encontraram indícios de que o desemprego atua como fator deletério sobre a saúde do trabalhador desempregado. Estes indivíduos acabam sofrendo com maior frequência e intensidade de sentimentos como baixa autoestima, ânimo e humor rebaixados, estresse, ansiedade, vergonha, humilhação, e também acabam apresentando distúrbios de sono.

Ao realizar uma revisão bibliográfica sobre os jovens e o desemprego, Guilland e Monteiro ${ }^{30}$ encontraram que $62 \%$ dos estudos analisados dizem respeito às consequências do desemprego sobre a saúde mental dos jovens, e tais resultados apontam que os desempregados são aqueles que apresentam maior prejuízo na saúde mental. Outros resultados também apontam que há uma maior prevalência de tabagismo entre os desempregados de longo prazo do que entre aqueles que se encontram no desemprego de curto prazo. Foram identificados, também, fatores de risco que aumentam a dificuldade de o jovem se inserir no mercado de trabalho: baixa escolaridade, situação financeira precária e pouca inserção em grupos sociais. Tal exclusão social pode influenciar negativamente na percepção das perspectivas que o jovem terá sobre o seu futuro, podendo aumentar o risco de que ele venha a fazer uso de substâncias psicoativas, de que participe de atividade criminais, ou, até mesmo, no desenvolvimento de uma ideação suicida.

Como pode ser visto, as fontes de sofrimento relacionado ao trabalho são diversas, mas normalmente estão ligadas a fatores comuns, como sobrecarga de trabalho, insatisfação com o trabalho, estresse, pressão, individualismo, falta de reconhecimento e consequente sentimento de desvalorização. O desemprego merece destaque como fonte de intenso sofrimento aos trabalhadores, mesmo entre aqueles que se encontram alocados dentro do mercado de trabalho, pois as pressões sofridas no contexto de trabalho adquirem um aspecto ainda mais aterrorizador quando o trabalhador pensa que a possibilidade de perder o emprego é real, e que não é necessário errar muito para que se perca o emprego.

Para Barros e Oliveira ${ }^{29}$ o desemprego é um problema cujas causas não residem somente numa questão individual, ele também está associado a uma série de transformações econômicas e histórias. No entanto, um discurso comum entre as pessoas para explicar o desemprego é a ociosidade e a preguiça dos desempregados, o que tende a aumentar o sofrimento dos desempregados e suas manifestações, citadas acima.

Os sinais, sintomas e consequências desse sofrimento são diversos, pois cada indivíduo tem a sua forma de manifestar o seu sofrimento, o que, às vezes, torna difícil a compreensão de sua fonte causadora. 


\section{Considerações finais}

A forma pela qual o homem se relaciona com o trabalho é diversa em vários aspectos, o que inclui características pessoais, o tipo de organização do trabalho, o conteúdo da tarefa, a importância que aquele trabalho tem na vida do sujeito, a possibilidade de o trabalhador ter liberdade suficiente de colocar algo de si no trabalho, e assim, se reconhecer naquilo que faz, o reconhecimento obtido pelo trabalho benfeito, as condições gerais de vida do trabalhador, suas relações interpessoais, sociais e o significado socialmente atribuído á função desempenhada, entre outros. Assim, é possível ver que existe uma teia complexa tecida entre o homem e o trabalho. A complexidade do campo em questão explica a diversidade de métodos de pesquisa na saúde mental relacionada ao trabalho, sendo que cada um tem suas limitações.

As publicações pesquisadas no período supracitado versaram especialmente sobre as diversas facetas do sofrimento relacionado ao trabalho a que os trabalhadores estão sujeitos. Apesar de as categorias de trabalho citadas nos estudos serem diversas, os artigos mencionaram aspectos em comum vividos como fatores de pressão no trabalho, aparentemente relacionados à lógica do mercado empresarial. Isto significa que, mesmo trabalhadores que lidam com a saúde, com questões sociais e até com o conhecimento, referem buscar incessantemente o aumento da produção, sentir que devem ser polivalentes, além de bons naquilo pelo qual foram contratados, também sentem que devem ser hábeis em lidar com as pessoas, pró-ativos, sempre buscando atualizar-se, disponíveis e competitivos, ao mesmo tempo em que devem ser cooperativos, entre outras características. Nas publicações, aparece como possível causa de sofrimento a experiência de falhar em alguma dessas tarefas, situação em que surge um sentimento de fracasso, o que pode levar a mecanismos de enfrentamento individuais, como o uso de entorpecentes e de medicamentos.

O sofrimento, vivido como fracasso individual em ambientes cada vez mais competitivos, geralmente é ocultado até que alcance um nível que impeça a continuidade da atividade. Essa lógica é desfavorável ao questionamento e à busca de melhorias na organização do trabalho.

Os artigos foram classificados de acordo com temas, de forma a tornar a exposição mais didática. No entanto, mesmo que cada pesquisa tivesse um assunto principal, este acabava se entrelaçando com diversos outros assuntos, o que demonstra, novamente, como o campo da Saúde Mental Relacionada ao Trabalho é complexo.

Dada a importância que o trabalho tem na vida das pessoas, o campo da saúde mental relacionada ao trabalho impõe importantes questões para as quais a psicologia pode contribuir de forma importante.

Masumoto LK; Faiman CJS. Mental health and work: a survey of Brazilian literature in Biblioteca Virtual da Saúde (BVS) databases. Saúde, Ética \& Justiça. 2014;19(1);1-11.

\begin{abstract}
This paper is a review of national literature regarding the relationship between mental health and work. Papers referring to this subject, published in the databases INDEXPsi, PePSIC and PSICODOC, in the period from 2008 to 2012, have been searched out. The descriptors "mental health" and "work" were used for the search that was carried out in the Brazilian Virtual Health Library (BVS - Bibioteca Virtual de Saúde). The 33 selected papers were distributed as follows in the databases: 12 from INDEXPsi, 8 from PePSIC and 13 from PSICODOC. The data of the publications were organized according to the most frequent issues, and were the following: the role of psychology and related knowledge within the field of Work-related Mental Health; work organization; ways of coping with suffering, risk factors and protection; suffering and illness. From the analysis of the texts, the authors point out that, with regard to the role of psychology as a tool of intervention, there seems to be a division between the performances of clinical psychologists and organizational psychologists, lacking integration between the differing approaches. Regarding factors that contribute to suffering / illness related to work, it turns out that aspects of work organization or management, lack of recognition, unattainable productivity goals, or jobs that result in isolation of the worker may have adverse effects on workers.
\end{abstract}

KEYWORDS: Mental Health; Occupational Health; Psychology.

\title{
Referências
}

1. Seligmann-Silva E. Desgaste mental no trabalho dominado. $1^{\text {a }}$ ed. Rio de Janeiro: Ed. Cortez-UFRJ; 1994.
2. Glina D, Rocha LE, Batista ML, Mendonça MGV. Saúde mental e trabalho: uma reflexão sobre o nexo com o trabalho 
e o diagnóstico, com base na prática. Cad Saúde Pública. 2001; 17(3):607-16. DOI: http://dx.doi.org/10.1590/S0102311X2001000300015

3. Braverman H. Trabalho e capital monopolista. $3^{a}$ ed. Rio de Janeiro: Zahar; 1981.

4. Dejours C. A loucura do trabalho. $5^{\text {a }}$ ed. São Paulo: Cortez; 1992.

5. Sato L. Saúde e controle no trabalho: feições de um antigo problema. In: Codo W, Jacques MG, organizadores. Saúde mental e trabalho: leituras. Petrópolis, RJ: Vozes; 2002. p. 31-49.

6. Abs D, Monteiro JK. Práticas da psicologia clínica em face do sofrimento psíquico causado pelo desemprego contemporâneo. Psicol Estud. 2010; 15(2):419-26. DOI: http://dx.doi.org/10.1590/S1413-73722010000200021

7. Gibert MAP, Cury VE. Saúde mental e trabalho: um estudo fenomenológico com psicólogos organizacionais. Bol Psicol. 2009; 59(130):45-60.

8. Bendassolli PF. Crítica às apropriações psicológicas do trabalho. Psicol Soc. 2011; 23(1):75-84. DOI: http://dx.doi. org/10.1590/S0102-71822011000100009

9. Carvalho GM, Moraes RD. Sobrecarga de trabalho e adoecimento no Polo Industrial de Manaus. Psicol Rev (Belo Horizonte). 2001; 17(3):465-82. DOI: http://dx.doi. org/10.5752/P.1678-9563.2011V17N3P465

10. Cassandre MP. Saúde dos docentes dos cursos stricto-sensu: os danos causados por imposições do processo avaliativo. Revista mal-estar e subjetividade. 2011; 11(2):779-816.

11. Cunha TB, Vieira SB. Entre o bordado e a renda: condições de trabalho e saúde das labirinteiras de Juarez Távora/ Paraíba. Psicol Ciênc Prof. 2009; 29(2):258-75.

12. Amato TC, Pavin T, Martins LF, Batista A, Ronzani TM Trabalho, gênero e saúde mental: uma pesquisa quantitativa e qualitativa entre bombeiros. Cad Psicol Soc Trab. 2010; 13(1):103-18.

13. Chies PV. Identidade de gênero e identidade profissional no campo do trabalho. Rev Estud Fem. 2010; 18(2):507-28. DOI: http://dx.doi.org/10.1590/S0104-026X2010000200013

14. Rotenberg L, Portela LF, Marcondes WB, Moreno C, Nascimento CP. Gênero e trabalho noturno: sono, cotidiano e vivência de quem troca a noite pelo dia. Cad Saúde Pública. 2001; 17(3):639-49. DOI: http://dx.doi.org/10.1590/S0102$311 \times 2001000300018$

15. Grisci CLI. Trabalho imaterial, controle rizomático e subjetividade no novo paradigma tecnológico. RAE eletrônica. 2008; 7(1): Art 4. DOI: http://dx.doi.org/10.1590/ S1676-56482008000100005

16. Merlo ARC, Traesel ES, Baierle TC. Trabalho imaterial e contemporaneidade: um estudo na perspectiva da Psicodinâmica do Trabalho. Arq Bras Psicol. 2011; 63(no. spe):94-104.
17. Secco IAO, Robazzi MLCC, Souza FEA, Shimizu DS. Cargas psíquicas de trabalho e desgaste dos trabalhadores de enfermagem de hospital de ensino do Paraná, Brasil. SMAD, Rev eletrônica saúde mental álcool e drog. 2010; 6(1):1-17. DOI: http://dx.doi.org/10.11606/issn.1806-6976.v6ilp1-17

18. Baierle TC, Merlo ARC. Saúde mental e subjetividade no trabalho de uma guarda municipal: estudo em psicodinâmica do trabalho. Cad Psicol Soc Trab. 2008; 11(1):69-81. DOI: http://dx.doi.org/10.11606/issn.1981-0490.v11i1p69-81

19. Castro TCM, Merlo ARC. Reconhecimento e saúde mental na atividade de segurança pública. Psico. 2011; 42(4):47480 .

20. Rumin CR, Ferrari RAN, Barros GIF, Cardozo WR, Cavalhero R. O sofrimento psíquico no trabalho de vigilância em prisões. Psicol Ciênc Prof. 2011; 31(1):188-99. DOI: http://dx.doi.org/10.1590/S1414-98932011000100016

21. Silva EA, Costa II. Saúde mental dos trabalhadores em saúde mental: estudo exploratório com os profissionais dos Centros de Atenção Psicossocial de Goiânia/GO. Psicol Rev (Belo Horizonte). 2008; 14(1):83-106.

22. Santos AFO, Cardoso CL. Profissionais de saúde mental: manifestação de stress e burnout. Estud Psicol (Campinas). 2010; 27(1):67-74. DOI: http://dx.doi.org/10.1590/S0103166X2010000100008

23. Bottega CG, Merlo ARC. Prazer e sofrimento no trabalho dos educadores sociais com adolescentes em situação de rua. Cad Psicol Soc Trab. 2010; 13(2):259-75. DOI: http://dx.doi. org/10.11606/issn.1981-0490.v13i2p259-275

24. Oliveira TTSS, Leme FRG, Godoy KRG. O cuidado começa na escuta: profissionais de saúde mental e as vicissitudes da prática. Mental. 2009; 7(12):119-38.

25. Santos C, Pereira KW, Carlotto MS. Burnout em profissionais que trabalham no atendimento a vítimas de violência. Barbarói. 2010; 32:69-81.

26. Bárbaro AM, Robazzi MLCC, Perdão LJ, Cyrillo RMZ, Suazo SVV. Transtornos mentais relacionados ao trabalho: revisão de literatura. SMAD, Rev eletrônica saúde mental álcool drog. 2009; 5(2):1-16.

27. Ribeiro SFR, Martins STF. Sofrimento psíquico do trabalhador da saúde da família na organização do trabalho. Psicol Estud. 2011; 16(2):241-50. DOI: http://dx.doi.org/10.1590/ S1413-73722011000200007

28. Ribeiro J, Pessalacia JDR, Mattos AA, Aramaki F, Postteli R. Saúde mental de trabalhadores de setores administrativos de uma empresa de construção civil e estruturas metálicas. SMAD, Rev eletrônica saúde mental álcool drog. 2009; 5(1):1-13. DOI: http://dx.doi.org/10.11606/issn.1806-6976. v5i1p1-13

29. Barros CA, Oliveira TL. Saúde mental de trabalhadores desempregados. Rev Psicol Organ Trab. 2009; 9(1):86-107.

30. Guilland R, Monteiro JK. Jovens e Desemprego: Estado da Arte. Rev Psicol Organ Trab. 2010; 10(2):145-58 